Bernal-Molina, Alicia.

Directora escénica y alumna de máster en música en la UPV.

Aldaz-Casanova, Claudio.

Artista plástico y profesor asociado en la Universidad de Murcia. Facultad de educación, Departamento de Expresión Plástica, Musical y Dinámica: Área de Didáctica de la Expresión Plástica.

\title{
Prolongación del alcance del significado de una obra plástica (o visual) mediante su sonorización.
}

\author{
TIPO DE TRABAJO:
}

Comunicación virtual.

PALABRAS CLAVE.

Corporación Bacilö, sesión sonora, Consume ESTO, LOCAL MODE, sonovisualización.

KEY WORDS.

Corporación Bacilö, sound sesión, Consume ESTO, LOCAL MODE, audio visualization.

\section{RESUMEN.}

Nuestro encuentro como colaboradores surge a partir del trabajo que desarrollamos dentro del colectivo Corporación Bacilö. Este grupo multidisciplinar desarrolla sus trabajos desde el 2003 en torno a la acción performativa o performance artística en la que el sonido tiene un gran protagonismo. La corporación está compuesta por distintas plataformas o microcorporaciones que desarrollan, cada una y paralelamente, su trabajo. Dos de ellas (Consume ESTO y LOCAL MODE) son los autores de esta propuesta de trabajo.

La propuesta de producción teórico-práctica, desarrollada junto a la línea de trabajo plástica del creador Claudio Aldaz, se basa en la relación entre lo plástico-visual y lo sonoro. El proyecto se realizó por primera vez en la clausura de la exposición TIMOCRACIA (noviembre de 2012) llevando a cabo una sesión audio-visual. Se partía de los trabajos de Aldaz que eran explicados en vivo por el propio autor con el acompañamiento de unas pautas sonoras improvisadas $y$ ejecutadas en vivo.

La línea de producción artística que planteamos consiste en la hibridación entre lo visual y lo sonoro. Proponemos un tipo de presentación de obra plástica (exposición) en la que intervenimos a partir de una sesión sonora improvisada que desarrollamos en vivo. Más que de un acompañamiento musical, se trata de la creación de un nuevo formato o pieza que conjuga la obra expuesta con la creación de ambientes o atmósferas que denominamos SONOVISUALIZACIÓN, en los que se amplía el término de escucha al estar vinculado a lo visual. El sonido nos remite a una dramaturgia que se materializa en las piezas plásticas que se exhiben. El espectador/observador se convierte en un escuchante de lo visual. La poética de lo visual y lo sonoro proponen un nuevo espacio expositivo donde el espectador está inmerso en una "puesta en escena total".

\section{ABSTRACT.}

Our starting point as collaborators come from the work we do within Corporación Bacilö. This multidisciplinary group has been developing their performative actions or artistic performances, in which sound plays a big part, since 2003. The corporation is composed of different platforms or micro-corporations that develop, both alone and in parallel, their work. Two of them (Consume ESTO and LOCAL MODE) are the authors of this proposal.

The theoretical-practical production, developed along the line of the plastic art of Claudio Aldaz, is based on the relationship between the visual and sound. The project was realized for the first time at the closing of the exhibition 
TIMOCRACIA (November 2012) with an audio-visual session that started from the works of Aldaz explained by himself to the accompaniment of sound scores improvised and performed live. The line of artistic production that we propose consists of the hybridization between the visual and the sonorous. We propose a type of presentation of plastic work (exhibition) in which we intervene with an improvised sound session that we develop live.

More than a musical accompaniment, it is the creation of a new format or piece that combines the exposed work with the creation of atmospheres that we call SOUNDVISUALIZATION, in which the term listening is extended to the visual. The sound gives us a dramaturgy that materializes in the plastic pieces that are exhibited. The viewer/observer becomes a listener of the visual. The poetics of the visual and the sound propose a new exhibition space where the viewer is immersed in a "total gesamtkunstwerk".

\section{CONTENIDO.}

"Algunas veces la imagen sigue al sonido y representa un papel secundario y no viceversa. El sonido es algo más que una simple ilustración de lo que está sucediendo en la pantalla."

Andrei Tarkovski

Este lugar de reflexión nos permite mostrar y analizar la experiencia que hemos denominado como sonovisualización, desarrollada para la clausura de la exposición de Claudio Aldaz Casanova, TIMOCRACIA que tuvo lugar en octubre de 2012 orquestada en colaboración con LOCAL MODE. Para poder describir el trabajo híbrido que desarrollamos en nuestra práctica conjunta se hace antes necesario explicar el modo de trabajo del grupo de acción performativa Corporación Bacilö.

El colectivo del que formamos parte, tiene una amplia experiencia en las Artes escénicas y audiovisuales y basa sus prácticas artísticas en la interacción y comunicación de los distintos artistas y lenguajes escénicos (vídeo, sonido, escenografía, iluminación...). Este grupo formado por siete artistas de diversa formación y procedencia (España, Noruega y Francia), nacidos entre la década de 1970 a 1983 , elabora sus productos en Murcia desde el año 2003. La procedencia artística del grupo es múltiple (arte plástico_visual, sonoro, performativo y escénico) y su trayectoria se sustenta en la interactuación de dichas artes. La corporación trabaja como laboratorio experiencial y basa sus prácticas artísticas en la "rearticulación del arte para el mundo dentro del sistema (o como ellos dicen para el $\left(\mathrm{MOMI}^{1}\right.$ ). Bacilö es para la sociedad actual un cuerpo o máquina, amorfa y crítica, que busca adeptos en masa (individualizadamente) para una nueva interpretación del mundo" ${ }^{2}$.

La Corporación es el brazo ejecutor y estructural con el que el colectivo lleva a cabo su labor satírica y crítica de la sociedad actual. Sus miembros-componentes son al mismo tiempo pseudo-científicos, agentes de control, sujetos actantes y técnicos-operarios que posibilitan los múltiples modos de intervención con el que trabajan: sesiones anti estrés, conferencias, conciertos, misas, ruedas de prensa, radio emisiones, mítines... Desde una experiencia activa Bacilö interviene por sorpresa, sea en un museo, un escenario o en un supermercado, creando "puestas en escena totales" ${ }^{3}$ en las que el testigo/paciente se ve envuelto en una ficción dialéctica con él mismo. Desde su creación, los productos Bacilö han sido diseminados en espacios artísticos dispares dada su capacidad de adaptación a cualquier medio de creación y han presentado sus trabajos en Festimad, Escena Contemporánea y Sala Siroco (Madrid), Digital Media (Valencia), Manifesta 8, SOS 4.8, Festival A Parte y AlterArte (Murcia), así como en los espacios públicos de las ciudades, centros comerciales y otros.

Uno de los elementos característicos de la plataforma es el ritual como forma escénica y la crítica directa a la sociedad actual, consumida por la tecnología y la banalidad. Para ello Bacilö se carga de una verborrea compleja, enrevesada y llena de referencias a la posmodernidad y sus iconos. Las actuaciones de Bacilö se convierten de esta forma en rituales esperpénticos de una sociedad tecnificada que anula al individuo. Podríamos decir que, como la homeopatía, pretende sanar un sistema consumido y corrupto, precisamente con la misma enfermedad. El audiovisual se convierte en el hilo conductor de su trabajo y desde el que cuestionar el actual sistema, en forma de terapias-rituales.

\footnotetext{
${ }^{1}$ Terminología de la propia corporación que se traduce como "Individuo medio o medio individuo".

${ }^{2}$ Material textual no editado de la corporación.

${ }^{3}$ Utilizando la terminología wagneriana expresión usada por la Corporación para definir las acciones, instalaciones y puestas en escena que llevan a cabo y remite al concepto acuñado por Wagner Gesamtkunstwerk cuando propone su drama musical. La obra de arte del futuro para Wagner se define como un drama comunitario que engloba y aglutina en una misma dirección a las distintas artes hacia una obra de arte total. (Wagner, 2011, p. 133).
} 


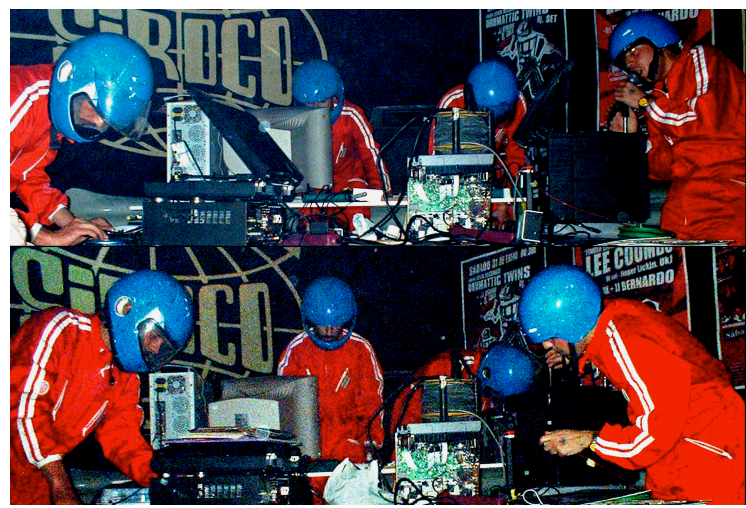

Ilustración 1: sala Siroco, Madrid 2004.

En estos rituales la concepción del espacio sonoro y visual sumergen al espectador en una suerte de lugar para el juego escénico en el que se convierte en protagonista, en paciente, pero no pasivo sino activo. A partir del largo desarrollo de estas partituras escénicas donde el error, la improvisación y la causalidad juegan un papel primordial, es desde donde partimos para crear otros espacios de exposición como este que denominamos sonovisualización.

Claudio Aldaz Casanova es un artista visual que desarrolla su trabajo en dos líneas fundamentales. Por un lado, el trabajo en el que desarrolla su obra plástica (escultura, pintura, obra gráfica...) firmada con su propio nombre y, por otro, la línea que tiene que ver con los nuevos media (vídeo, instalación, escenografía, performance...) que plantea con la plataforma consume ESTO con la que, aparte de producir obra específica, se dedica a producir, coordinar o hibridar, proyectos en solitario o junto a otros artistas y colectivos. En este caso la propuesta conjunta de hibridación planteaba una colaboración sonoro-visual entre dos de las corporaciones que forman parte de Bacilö, (la de consume ESTO con LOCAL MODE), para dar cierre a una exposición del artista. Ésta se llevó a cabo en el espacio de gestión cultural independiente La Azotea, en la clausura de la exposición TIMOCRACIA, en la que se mostraban una serie de dibujos y collages creados desde la indignación contra el sistema bancario en particular.

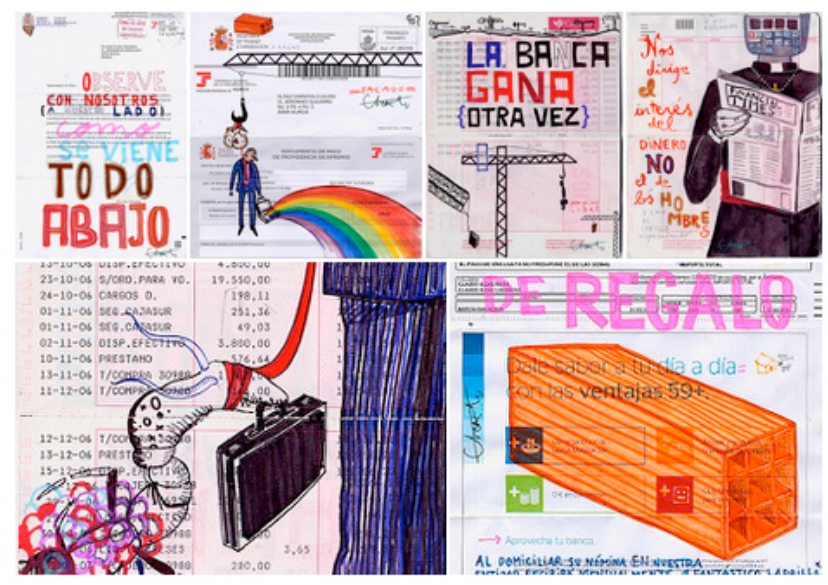

Ilustración 2: Selección de algunos dibujos de la exposición. Sala La Azotea (Murcia), 2012.

Los dibujos eran un guiño, desde la ironía, a la situación actual, al contexto de crisis en que nos encontramos inmersos desde 2008, de crisis económica pero también de crisis ideológica, de crisis de los valores que rigen la sociedad occidental, y del "agotamiento" individual y colectivo. Este planteamiento de crítica irónica y sarcástica a la actual situación, es precisamente lo que pretendía escenificar la sesión sonora audiovisual. Una sesión o partitura con pautas improvisadas en la que el autor de la exposición procedía a una "explicación" o desarrollo de los contenidos de las distintas obras con un acompañamiento sonoro ejecutado en directo. El autor ejercía de "narrador" a la vez que de intérprete sonoro mientras los ambientes y paisajes sonoros acompañaban la visualización de un número amplio de piezas cuya elección se veía condicionada así mismo por el ambiente sonoro creado. De esta relación entre lo visual y lo sonoro, de este nuevo espacio expositivo, es desde donde comenzamos a reflexionar en torno a la prolongación del alcance del significado de una obra visual y su consecuente modificación de la observación/escucha. 
Para nosotros el término sonovisualización hace referencia al proceso de creación de una partitura audiovisual que puede ser guiada por el sonido ejerciendo de protagonista o viceversa, siendo la imagen la que marca/guía/determina el ritmo, el tono, el momento de salto/cambio de una imagen a otra. De este modo la imagen navega a través de las melodías y atmósferas sugeridas por el sonido o al contrario. No se trata tanto de hacer que lo visual esté anclado al ritmo de lo sonoro, sino más bien de hacer que los dos lenguajes participen del dúo y sean guías de la sesión. En términos coreográficos se trataría de que en algunos momentos la imagen lleve a lo sonoro y que en otros sea llevada.

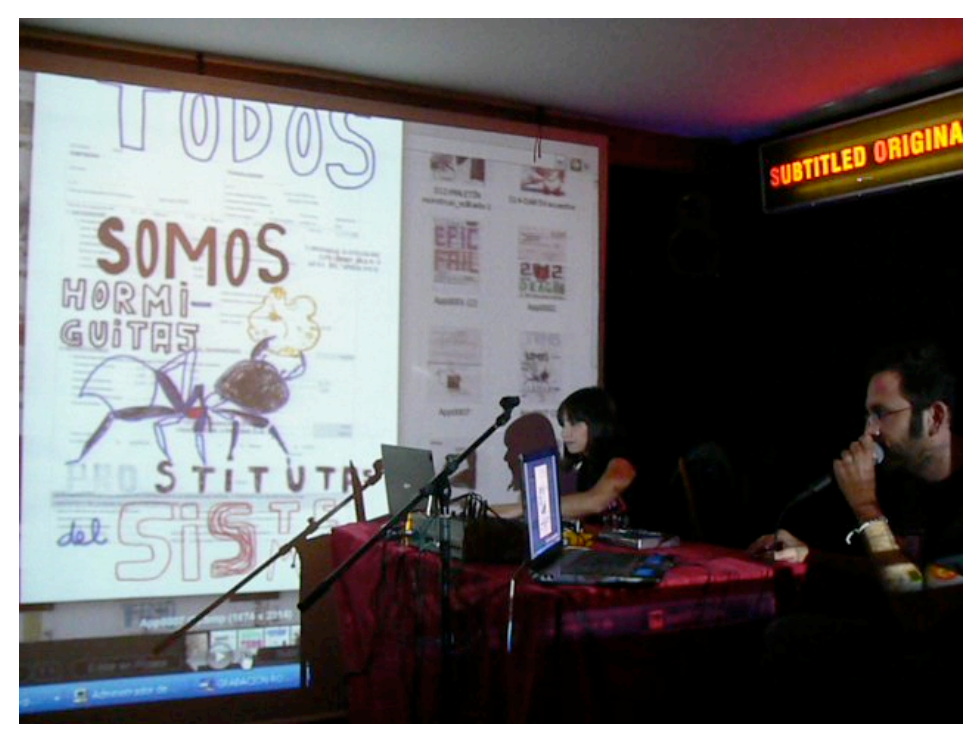

Ilustración 3: sesión Timocracia. Sala La Azotea (Murcia), 2012.

Para ello es preciso que el intérprete de la narración visual conecte y se deje llevar por la improvisación sonora de la que está formando parte como conductor oral y ejecutante de la misma. Se convierte su acción entonces en una narración poética que hace viajar al espectador por la letra pequeña ${ }^{4}$, por los pequeños detalles, por las sutiles y no tan sutiles ironías visuales que al ser amplificadas (tanto visual como sonoramente) se cargan de significado para el observador.

En este caso se trató de un formato de narración progresivo y lineal propiciada por los contenidos de corte figurativo de la obra en cuestión, pero las posibilidades de experimentación se abren a múltiples campos estéticos, como la abstracción, en los que la interpretación puede ser "más libre", si queremos decirlo así o que no tienda a un significado cerrado. En cualquiera de los casos, el término de escucha/observador se amplía, no sólo por los distintos significados que aporta la relación entre lo visual y lo sonoro sino porque propone al espectador una focalización (la mirada y escucha) concreta de su mirada y consigue crear, de esta manera, distintos planos como en el lenguaje cinematográfico.

La narración visual y la narración sonora comparten ritmos e intenciones, pero discurren libremente durante la sesión pues el trabajo desde el que partimos (pautas de improvisación) hace que generemos estructuras o partituras en las que nos movemos libremente. En este sentido nos parece interesante la definición que da Bourriaud del Dj:

"su trabajo consiste a la vez en proponer un recorrido personal por el universo musical (su playlist) y enlazar dichos elementos en un determinado orden, cuidando sus enlaces al igual que la construcción de un ambiente (actúa en caliente sobre la multitud de bailarines y pude reaccionar ante sus movimientos)" (Bourriaud, 2011, p. 43).

Al igual que el $\mathrm{Dj}$, el Vj (que trabaja con imágenes y vídeo) propone un recorrido o viaje visual. En nuestro caso más que hacer que el público reaccione a nuestra propuesta, pretendemos crear una dramaturgia de lo visual y lo sonoro con un tipo de formato que hibrida entre la instalación, el arte sonoro y el arte plástico.

\footnotetext{
${ }^{4}$ En este caso la letra pequeña es literal porque el soporte de estos dibujos son las distintas cartas y documentos oficiales que el artista ha recibido a su nombre y en su domicilio desde las distintas administraciones de una experiencia autónoma-empresarial pasada.
} 
Algunas notas sobre consume ESTO.

Consume ESTO es una plataforma de acción artística que se desenvuelve en formatos de creación muy dispares: instalación, acción performativa, audiovisual, propaganda... En sus planteamientos iniciales se interesa por las relaciones de hoy día entre arte y publicidad manifiestas en nuestra cultura (NO TENEMOS SUEÑOS BARATOS 2015) Consume ESTO (Palacio Aguirre de Cartagena 2001, Yesqueros Espacio Joven de Murcia 2003, MUA 2004), Arte vs. Publicidad ((Re)visiones críticas desde el arte actual. Prensas de la Universidad de Zaragoza, 2016), desarrollando propuestas que fusionan, interactúan y asimilan las múltiples posibilidades comunicativas, conceptuales y estéticas que esta relación nos ofrece; reflexionando sobre el lenguaje, el significado y los circuitos comunicativos en la sociedad. Otras intervenciones en entornos urbanos (Restos Arqueológicos del S.XX 2003 y 2008, FARDOSOFÁ 2010) reflejan su interés por interpelar de manera crítica al espectador, intentando que establezca un dialogo interno consigo mismo.

De un tiempo a esta parte, además de su producción propia, ha fijado su atención en la creación y coordinación de proyectos en relación con otras entidades y colectivos, ya sea fusionando sus propuestas o apoyando nuevas iniciativas (ajenas). Así es como surgen sus colaboraciones asiduas con Corporación Bacilö (N.P.N.R en el Museo de la Universidad de Alicante, 2004) en un proyecto comisariado por Consume ESTO, o como la que nos ocupa en esta ocasión con LOCAL MODE.

Sus planteamientos en el campo sonoro se fijan en las posibilidades comunicativas, conceptuales y estéticas del sonido en su acepción más amplia. Reflexionando sobre este elemento como lenguaje, significante y significado. Define la mayoría de sus producciones sonoras como paisajes, viajes o ambientaciones sonoras que a su vez se podrían enmarcar dentro de lo que habitualmente se ha considerado arte sonoro, spoken word, ruidismo o poesía sonora.

En el campo del arte sonoro o el sonido, insistimos en su acepción más amplia, ha colaborado asiduamente con Corporación Bacilö, Sodoma\&Modorra, New Models for a New Battle y artistas como Pedro Guirao o Raúl Frutos de Crudo Pimento (Proyecto EMET 2014).

Algunas notas sobre LOCAL MODE.

Se crea como plataforma desde la que desarrollar propuestas o intervenciones con carácter público y socializador, generalmente urbanas en el ámbito de las artes escénicas. Esta plataforma canaliza proyectos colectivos e individuales que se acercan más a la acción performativa y al arte visual (desde la instalación sonora a la escenografía). LOCAL MODE trabaja qué es la escena desde lo cotidiano. De ahí que las diversas acciones y talleres que produce sean de orden social o en entornos urbanos preferiblemente (ESTAXI para Manifesta 8, SÁCALO en la Fragua de Murcia, Infinitamente a tiempo en el III Simposio di arte a tema Montagnarte 2015 en Cutigliano (Italia)). También desde esta plataforma desarrolla piezas de arte sonoro o sesiones audiovisuales que lleva a cabo con el dúo SODOMA\&MODORRA [https://soundcloud.com/sodomaetmodorra] y su activa colaboración con Corporación Bacilö desde el 2013.

Sus investigaciones giran en torno al lenguaje sonoro como fuente de creación dramática y en las posibilidades del hecho escénico. Lleva a cabo desde propuestas de espacio sonoro para obras teatrales (como en 016 Ejercicio fallido para mujeres 2014), hasta instalaciones objetuales (Pink Jail Box en el Rincón Obsoleto de Medialab Prado de Madrid) pero en todo momento el interés de la plataforma se vincula en torno a las nuevas prácticas escénicas y los territorios fronterizos.

\section{CONCLUSIONES.}

Podemos decir, a raíz de la experiencia realizada, que efectivamente el significado y las implicaciones conceptuales y estéticas se prolongan en múltiples sentidos y direcciones cuando relacionamos el lenguaje visual con el lenguaje sonoro. Con este tipo de formato expositivo o experiencia expositiva creemos, en palabras de Tarkovski que "la música no solo refuerza e ilustra un contenido vertido en imágenes paralelas a la música, sino que abre la posibilidad de una impresión nueva, cualitativamente distinta, del mismo material" ${ }^{5}$. La capacidad de amplificación que tiene el sonido respecto de una imagen (o de amplificación en el contraste) es cosa ampliamente estudiada en el cine, pero creemos que no suele darse tan a menudo en otras formas expositivas. "La introducción del elemento musical modifica el colorido, a veces incluso la sustancia de esa vida fijada en un plano" ${ }^{6}$.

Por otro lado, creemos que nuestras investigaciones ligadas a terrenos fronterizos entre la instalación, el arte sonoro y la exposición visual, no solo fomentan la inter, multi, pluri y transdisciplinariedad de las artes, sino que reflexionan sobre la percepción estética y los nuevos modos de consumo del arte (desde la producción). En este sentido la ejecución en vivo o en directo va más allá del músico que toca, ahora es el artista que presenta, representa y ejecuta una obra visual. La tecnología nos permite amplificar el significado de la obra y dotarlo de un sentido más amplio sea desde el acompañamiento o desde el contraste.

\footnotetext{
${ }^{5}$ Tarkovski, A. 2002, p. 186

${ }^{6}$ Idem.
} 
Nuestra propuesta, que denominamos sonovisualización, se construye como partitura que se concibe como estructura o esquema de la relación entre los textos orales, las atmósferas sonoras y el viaje visual. Estos tres elementos tienen el mismo peso narrativo en la sesión, aunque a veces la significación recaiga momentáneamente sobre uno de ellos. El poder que tiene el sonido de otorgar significación (que no narración en el sentido lineal de una historia) a la imagen y de aportar otras significaciones, es precisamente lo que nos interesa de este trabajo. Proponemos otras formas de mirar y de escuchar.

\section{OTRAS EXPERIENCIAS AFINES.}

A la hora de hablar de un concepto en construcción como este es inevitable acudir a referencias simultáneas y/o previas que participan de planteamientos similares, aunque probablemente con intenciones distintas como el trabajo de Chris Cunningham y Alva Noto. El primero es un vídeo-artista y director inglés que ha realizado diversos shows audiovisuales en directo (Flex, Monkey drummer y Rubber Johnny) en los que cabe preguntarse si es la música (o el sonido) la que condiciona el ritmo y el tipo de imágenes o es a la inversa. En cualquier caso, se trata de sesiones con material pre-obtenido/pre-grabado, esto es, se dispone previamente de ambas fuentes, tanto el material sonoro como el visual, que se disponen en distintos dispositivos multipista y son lanzados en directo, estando, por tanto, limitada la improvisación. Al tratarse de espectáculos que suelen presentarse en eventos como festivales musicales, de alguna forma podríamos decir que se trata de una sesión de post-producción en vivo en la que el viaje audiovisual ha sido preestablecido de manera más o menos precisa. La simbiosis de imagen y sonido conforma un todo en el que es difícil discernir cuál de las dos partes predomina sobre la otra.

El segundo ejemplo que recogemos aquí es el de Alva Noto. En las producciones del músico alemán, Carsten Nicolai, encontramos otra manera de sonorizar la imagen o visualizar el sonido. En este caso a través de programas que "traducen" en imágenes la composición sonora y otros que la sincronizan. Las piezas a las que nos referimos son m6re, uni acronym (feat. anne-james chaton), diamond version live y la colaboración con el artista Ryuichi Sakamoto Insen Live.

\section{CONCLUSIONES}

Podemos decir, a raíz de la experiencia realizada, que efectivamente el significado y las implicaciones conceptuales y estéticas se prolongan en múltiples sentidos y direcciones cuando relacionamos el lenguaje visual con el lenguaje sonoro. Con este tipo de formato expositivo o experiencia expositiva creemos, en palabras de Tarkovski que "la música no solo refuerza e ilustra un contenido vertido en imágenes paralelas a la música, sino que abre la posibilidad de una impresión nueva, cualitativamente distinta, del mismo material ${ }^{\prime 7}$. La capacidad de amplificación que tiene el sonido respecto de una imagen (o de amplificación en el contraste) es cosa ampliamente estudiada en el cine, pero creemos que no suele darse tan a menudo en otras formas expositivas. "La introducción del elemento musical modifica el colorido, a veces incluso la sustancia de esa vida fijada en un plano" ${ }^{8}$.

Por otro lado, creemos que nuestras investigaciones ligadas a terrenos fronterizos entre la instalación, el arte sonoro y la exposición visual, no solo fomentan la inter, multi, pluri y transdisciplinariedad de las artes, sino que reflexionan sobre la percepción estética y los nuevos modos de consumo del arte (desde la producción). En este sentido la ejecución en vivo o en directo va más allá del músico que toca, ahora es el artista que presenta, representa y ejecuta una obra visual. La tecnología nos permite amplificar el significado de la obra y dotarlo de un sentido más amplio sea desde el acompañamiento o desde el contraste.

Nuestra propuesta, que denominamos sonovisualización, se construye como partitura que se concibe como estructura o esquema de la relación entre los textos orales, las atmósferas sonoras y el viaje visual. Estos tres elementos tienen el mismo peso narrativo en la sesión, aunque a veces la significación recaiga momentáneamente sobre uno de ellos. El poder que tiene el sonido de otorgar significación (que no narración en el sentido lineal de una historia) a la imagen y de aportar otras significaciones, es precisamente lo que nos interesa de este trabajo. Proponemos otras formas de mirar y de escuchar.

\footnotetext{
${ }^{7}$ Tarkovski, A. 2002, p. 186

${ }^{8}$ Idem.
} 
Bernal-Molina, Alicia; Aldaz-Casanova, Claudio

Prolongación del alcance del significado de una obra plástica (o visual) mediante su sonorización

III CONGRESO INTERNACIONAL DE INVESTIGACIÓN EN ARTES VISUALES :: ANIAV 2017 ::GLOCAL [codificar, mediar, transformar, vivir] http://dx.doi.org/10.4995/ANIAV.2017.4930

\section{FUENTES REFERENCIALES.}

Bacilö: Corporación Bacilö 2010. [http://corporacionbacilo.blogspot.com/]. [ Consulta el 28/02/2017].

BOURRIAUD, Nicolas.: Post producción. Adriana Hidalgo editora, Buenos Aires, 2004.

Consume ESTO: (Re)visiones críticas desde el arte actual. Prensas de la Universidad de Zaragoza, 2016, p.88-87.

NICOLAI, Cartsen: Alva Noto, 1997 [http://www.alvanoto.com/]. [Consultado el 28/02/2017].

TARKOVSKI, Andrei: Esculpir en el tiempo. Reflexiones sobre el arte, la estética y la poética del cine. Ediciones Rialp, Madrid, 2002.

WAGNER, Richard: El arte del futuro. Prometeo libros, Buenos aires, 2011. 